\title{
LONDRINA E A PRAÇA MARECHAL FLORIANO PEIXOTO
}

\author{
Camila Lima Chechin Camacho Arrebola ${ }^{1}$
}

Silvana de Jesus Galdino ${ }^{2}$

Bruno Luiz Domingos De Angelis ${ }^{3}$

\begin{abstract}
RESUMO
O presente artigo visa realizar uma avaliação urbanística da Praça Marechal Floriano Peixoto, conhecida como Praça da Matriz, localizado na área central do município de Londrina, Estado do Paraná. Propondo a avaliação do contexto e da importância desta praça para a cidade; investigando a história, o seu papel em relação ao entorno, a dinâmica e a estruturas físicas. A metodologia proposta consiste na avaliação do processo de reconstrução histórica destes espaços urbanos, buscando através da análise de documentos oficiais do executivo e legislativo municipal, iconografias, jornais, revistas, livros, fatos e acontecimentos políticos; a identificação da forma de pertencimento da praça junto à população. Além de pesquisa de campo, entrevistas, aplicação de questionários junto aos usuários e moradores; objetivando a análise reflexiva sobre a estrutura urbana. Para através desta pesquisa realizar uma reflexão acerca do planejamento urbano, avaliando a forma como as praças interferem no contexto social.
\end{abstract}

PALAVRAS-CHAVE: Praça. História. Avaliação.

\section{LONDRINA AND SQUARE MARECHAL FLORIANO PEIXOTO}

\footnotetext{
${ }^{1}$ Arquiteta e Urbanista, Mestranda da Universidade Estadual de Maringá no Programa de Pósgraduação em Engenharia Urbana. carrebola_3@hotmail.com.

2 Geógrafa, Mestranda da Universidade Estadual de Maringá no Programa de Pós-graduação em Engenharia Urbana. silgaldino@outlook.com.

${ }^{3}$ Agrônomo, Professor do Departamento de Agronomia da Universidade Estadual de Maringá. brucagen@uol.com.br.
} 


\begin{abstract}
This article aims to conduct an assessment of urban Praça Marechal Floriano Peixoto, known as Cathedral Square, located in the central area of Londrina, Paraná State. Proposing the assessment of the context and importance of the square to the city; investigating the history, its role in relation to surroundings, dynamics and physical structures. The proposed methodology consists of evaluating the historical reconstruction of these urban spaces process, searching through the analysis of official documents of the municipal executive and legislative, iconography, newspapers, magazines, books, events and political events, the identification of the square form of belonging together the population. In addition to field research, interviews, questionnaires with users and residents; aiming at reflexive analysis on urban structure. To conduct this research through a reflection on urban planning, assessing how the squares interfere in the social context.
\end{abstract}

KEY-WORDS: Square. History. Evaluation.

\title{
LONDRINA Y PLAZA MARECHAL FLORIANO PEIXOTO
}

\section{RESUMEN}

Este artículo tiene como objetivo realizar una evaluación de la Praça Marechal Floriano Peixoto urbana, conocida como Plaza de la Catedral, ubicado en la zona central de Londrina, estado de Paraná. Proponer la evaluación del contexto y la importancia de la plaza de la ciudad; la investigación de la historia, su papel en relación al entorno, la dinámica y estructuras físicas. La metodología propuesta consiste en la evaluación de la reconstrucción histórica de estos procesos espacios urbanos, buscando a través del análisis de documentos oficiales del ejecutivo municipal y, iconografía, periódicos, revistas, libros, eventos legislativos y los acontecimientos políticos, la identificación de la forma cuadrada de pertenencia la población. Además de la investigación de campo, entrevistas, cuestionarios con los usuarios y residentes; con el objetivo de análisis reflexivo sobre la estructura urbana. Para realizar esta investigación a través de una reflexión sobre la planificación urbana, la evaluación de cómo las plazas interfieren en el contexto social.

PALABRAS-CLAVE Square. Historia. Evaluación.

\section{INTRODUÇÃO}

O ser humano convive em sociedade com outros indivíduos através do meio em que vive. A cidade interage com grupos que configuram suas paisagens, na qual o homem estrutura elementos e organiza as formas urbanas e através de laços sociais constrói seus espaços de vivência urbana. Os lugares são produtos das sociedades e suas manifestações sociais; sejam elas econômicas, históricas e simbólicas configurando diferentes formas espaciais.

A praça é um espaço historicamente voltado para a vivência; pois são nas praças públicas que ocorrem às práticas comerciais, de lazer, manifestações artísticas, religiosas e políticas, mas principalmente a sociabilidade e o registro da memória urbana. 
O município de Londrina/PR, esta em constante crescimento. Atualmente exerce grande influência no Sul do País e contribui muito para a economia brasileira, sendo referência nas áreas de telecomunicação, tecnologia, saúde, agronegócio e prestação de serviço. Possui um polo universitário de grande importância, inúmeros hospitais, restaurantes, bares, lojas e shoppings. No momento vive a era do desenvolvimento industrial e atraindo cada vez mais investimentos para a região (LONDRINA, 2000).

Possui 506.701 habitantes e está localizado ao Norte do Estado do Paraná, na macrorregião do Sul do Brasil. Sua área é 1.653,075 Km²; a região de Londrina encontra-se limítrofe aos municípios de Marilândia do Sul, Apucarana, Arapongas, Assaí, Cambé, Ibiporã, São Jerônimo da Serra, Sertanópolis e Tamarana. E encontra-se dividida em oito distritos e uma sede administrativa, são estes: o distrito de Espírito Santo; Guaravera; Irerê; Lerroville; Maravilha; Paiquerê; São Luiz e Warta (LONDRINA, 2000; IBGE, 2014).

Apresenta 241 praças distribuídas por toda a área urbana, com concentração na área central; dos $245.52 \mathrm{Km}^{2}$ de área urbana, 16,25\% correspondem aos espaços livres de uso público e que estão divididos em: praça, parque, fundo de vale e lagos (LONDRINA, 2014).

Esta pesquisa tem como objetivo avaliar um espaço público de lazer do município de Londrina, através de avaliações, de pesquisa de campo, aplicação de questionário, entrevistas com usuários e moradores das áreas proximidades, enfocando informações sobre o mobiliário, equipamentos de lazer, áreas de esporte bem como a percepção do usuário. Após a aquisição das informações será elaborado um diagnóstico da praça e em seguida realizada reflexão sobre o planejamento urbano.

\section{REVISÃO BIBLIOGRÁFICA}

As ágoras eram os principais espaços que compunham as antigas cidades gregas. Espaços livres nos quais a comunidade utilizava como território democrático no qual realizavam atividades comerciais, políticas, religiosas e culturais. Era um ambiente de convivência, reduto de tradições, centro de decisões importantes do 


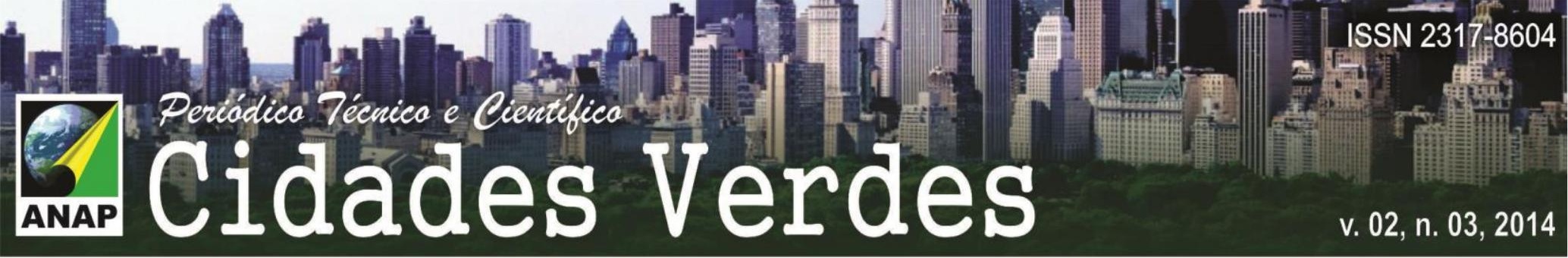

cidadão grego. Considerada como um símbolo da democracia, onde todos tinham direito de voz e voto (SALDANHA, 2011).

Era o ponto de convergência de tudo que não era oficial, de certa forma gozava de um direito de 'extraterritorialidade' no mundo da ordem e da ideologia oficial, e o povo aí tinha sempre a última palavra (SEGAWA, 1996).

E foi a partir das necessidades de espaços para abrigar as festividades, encontros, atividades de troca, que surgiram às praças e na sua evolução tornaramse áreas centrais urbanas (SILVA et al., 2011).

Segundo Segawa (1996) as "piazzas" italianas abrigavam rituais de variada natureza, religiosos ou seculares; já nas espanholas, a "plaza mayor" situava-se distante do centro urbano, muitas vezes intramuros.

Para Andrade e Bovo (2010), no Brasil o surgimento das primeiras praças ocorreu em frente às Igrejas. Tais logradouros atraiam as residências mais luxuosas. A importância destes espaços traz para seu entorno sofisticadas residências, prédios públicos e o comércio (GONÇALVES et al., 2007).

A praça deve sua existência, sobretudo, aos adros das nossas igrejas. Se tradicionalmente essa dívida é válida, mais recentemente a praça tem sido confundida com jardim. A praça como tal, para reunião de gente e para um sem número de atividades diferentes, surgiu entre nós, de maneira marcante e típica, diante de capelas ou igrejas, de conventos ou irmandades religiosas. Destacava, aqui e ali, na paisagem urbana estes estabelecimentos de prestígio social. Realçava-Ihes os edifícios; acolhia os seus frequentadores (MARX, 1980).

Diferente das praças medievais europeias, nas praças coloniais brasileiras realizavam-se todas as atividades no mesmo espaço; independente de serem eventos civis ou militares. Funcionando como um espaço polivalente; palco de muitas manifestações dos costumes e hábitos da população, lugar de articulação entre os diversos estratos da sociedade colonial (ROBBA e MACEDO, 2003).

E na mudança do século XVIII para o XIX surgem os primeiros espaços ajardinados de uso coletivo nas cidades brasileiras. Com a influência cultural realizada pela França e Inglaterra, surgem campanhas de modernização, salubridade e embelezamento das cidades. A proposta leva a demolição de 


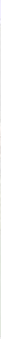

propriedades, o desalojamento e transferência da população pobre, seguida da construção de praças e grandes avenidas ajardinadas. A praça passa a ser um belo cenário ajardinado objetivando o lazer, a reflexão, o entretenimento, a convivência da população e o passeio, com valorização do uso de vegetação na cidade como forma de amenizar os efeitos da urbanização dos grandes centros (MACEDO; ROBBA, 2003).

Os espaços livres de uso público, como as praças e parques, são de grande importância para a qualidade ambiental e de vida da população. Para Da Silva (2012), estes ambientes facilitam a prática de atividades físicas. E a vegetação presente nos novos espaços ajardinados são componentes importantes na paisagem urbana. $\mathrm{O}$ contato com a natureza age no homem como um atenuante mental, proporcionando um relaxamento (SILVEIRA e BARROS, 2001).

No Brasil o início da arborização, de forma planejada, ocorre ao mesmo tempo em que a evolução das funções das praças. De espaços livres passam a ser implantadas como jardins (GOMES, 2005).

A criação do Jardim Botânico e do Parque D. Pedro II, em São Paulo, constituiu em uma estratégia de ocupação de área com pouca possibilidade de ocupação. E nos anos 1950, o parque do lbirapuera surge também em terrenos de pouca qualidade (SEGAWA, 1996). Assim aos mesmos modos que nas antigas cidades europeias, os primeiros jardins públicos brasileiros foram criados ao redor das cidades e em terras com condições topográficas desfavoráveis a urbanização, embora sendo áreas verdes com pouco planejamento (MARX, 1980).

A praça é um lugar especial, segundo De Angelis \& De Angelis Neto (1999), não é apenas um vazio na estrutura urbana, detém valor funcional, político-social, simbólico e artístico. Caracteriza-se pelo contraste com a malha urbana que a cerca, o jogo dos cheios e vazios, rompendo com a continuidade da cidade, provocando surpresa e descontração nas pessoas (MELO; ROMANINI, 2008). No transcorrer dos anos perdeu seu poder de ser informativa, embora tenha mantido o poder aglutinador. E continua sendo um importante espaço livre e público, comum a toda a sociedade, servindo como local de lazer e área verde pública (BOVO e ANDRADE, 2012). 
Uma nova proposta de praça, segundo De Angelis \& De Angelis Neto (2000), criada pelos americanos junto aos shopping-centers são as praças de alimentação. Além desta ainda existem outros modelos, que propõem espaços mais direcionados ao lazer e entretenimento, e para isso são inseridas quadras poliesportivas, brinquedos, pistas de caminhada, espaços para o lazer cultural, além da inserção da paisagem natural em seu espaço.

Bovo e Andrade (2012), afirmam ainda que frente às probabilidades de lazer oferecidas pelas novas tecnologias às praças públicas tornam-se pouco frequentadas, uma vez que as cidades não garantem a segurança da população. Nos grandes centros, são encontradas, com facilidade, praças deterioradas e pouco frequentadas devido à diversidade de problemas que envolvem tais espaços. Isso constitui para os planejadores, uma importante questão no que se refere à qualidade da paisagem urbana e à valorização dos espaços públicos. Somado ao aumento populacional se faz necessário que exista a ampliação dos equipamentos urbanos, uma vez que o território passa a ser solicitado por um número crescente de habitantes (GOMES, 2005).

A apropriação dos espaços é uma das condições para a criação dos lugares e a identificação das pessoas com a cidade. $O$ contato com a realidade dos espaços avaliados favorecerá a compreensão do uso e a dinâmica de funcionamento do local (MENEGUETTI, 2005).

Atualmente, no Brasil, as Secretarias Municipais do Meio Ambiente e de Planejamento Urbano têm a função de distribuir regularmente as praças e a presença da vegetação ao longo da malha urbana, para torná-las mais atraentes e adequadas à realização do lazer, tendo como base a Lei 6.766/1979 (BRASIL, 2014), que fala do parcelamento do solo urbano.

Como instrumento para coleta de dados foi utilizado os formulários apresentados por De Angelis (2000) em sua tese de doutorado intitulada: "A praça no contexto das cidades: o caso de Maringá PR".

O instrumento trata do perfil dos usuários, através de uma enquete com questões abertas e de múltipla escolha. Nele são colhidas características socioeconômicas, identificação dos hábitos da população com relação aos espaços livres de uso público. E também foi aplicado o formulário quantitativo que verificar a 


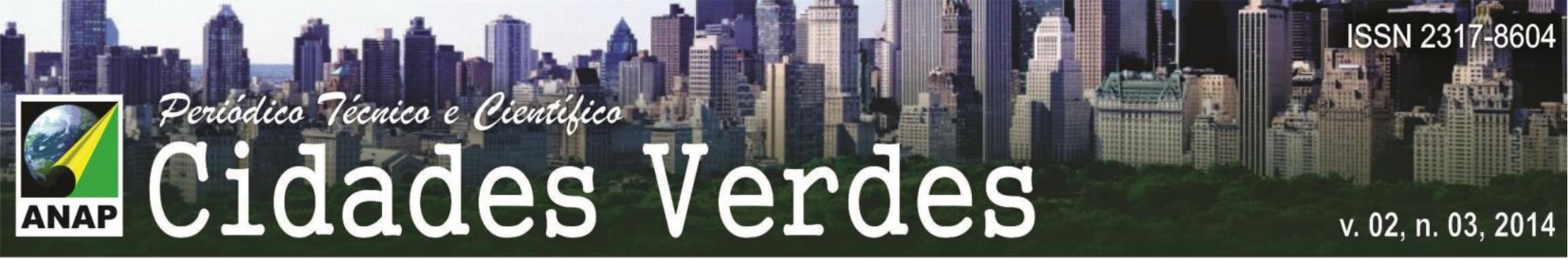

existência ou não de equipamentos e infraestruturas. O formulário qualitativo traz a proposta de avaliar o estado de conservação dos equipamentos e infraestrutura presentes, sendo também avaliados quesitos relativos às percepções dos usuários sobre o ambiente.

\section{MATERIAIS E MÉTODOS}

O presente artigo objetiva avaliar a Praça Marechal Floriano Peixoto, através de pesquisa de campo, sendo realizadas visitas e entrevistas com usuários e moradores das áreas circunvizinhas.

O usual para obtenção de resultados confiáveis é calcular estatisticamente a amostra a ser aplicada a partir do número de habitantes da cidade, mas por ser um local público, as praças possuem características de fluxo variado. Assim tratando-se de espaço público não é possível definir a amostra e optou-se por realizar 50 entrevistas, possibilitando o tratamento estatístico através de uma distribuição normal. O questionário foi testado anteriormente em outra praça como amostra piloto, com um número reduzido de usuários.

Os questionários foram aplicados em três dias sequencias da semana no mês de agosto de 2014, no período matutino. A proposta deste instrumento e buscar informações acerca das percepções e expectativas dos usuários e moradores das áreas adjacentes.

A proposta é obter uma avaliação da importância histórica da praça em relação à cidade além de investigar o uso e funções do entorno, localização, dimensões, traçado, topografia, infraestruturas, conservação, acessibilidade, mobiliário, paisagismo e as atitudes comportamentais dos usuários em relação ao ambiente.

\section{RESULTADOS E CONSIDERAÇÕES}

A Praça Marechal Floriano Peixoto é um marco na histórico da cidade de Londrina, surgiu junto com o traçado do município. O Engenheiro Alexandre Rasgulaeff, autor do projeto desenvolveu seu traçado em formato de asterisco, 


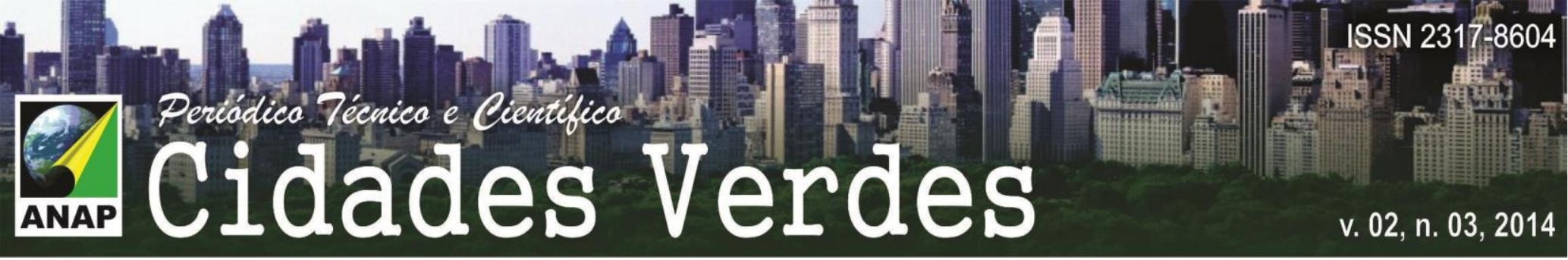

muitos autores afirmam que seu desenho remete a bandeira da Inglaterra, já outros dizem que foram os caminhos traçados pelos primeiro moradores do município.

Ela vista pela face lateral maior, através do Jardim, reforça a importância do local e seu valor simbólico, por dar melhor visibilidade do seu desenho. Embora fosse um espaço estratégico, o lugar não tinha um nome oficial, sendo conhecido como a Praça da Matriz ou Praça da Bandeira. Inaugurada em 7 de setembro de 1934 com o nome de Praça Marechal Floriano (Figura 1).

Figura 1: Praça na década de 30

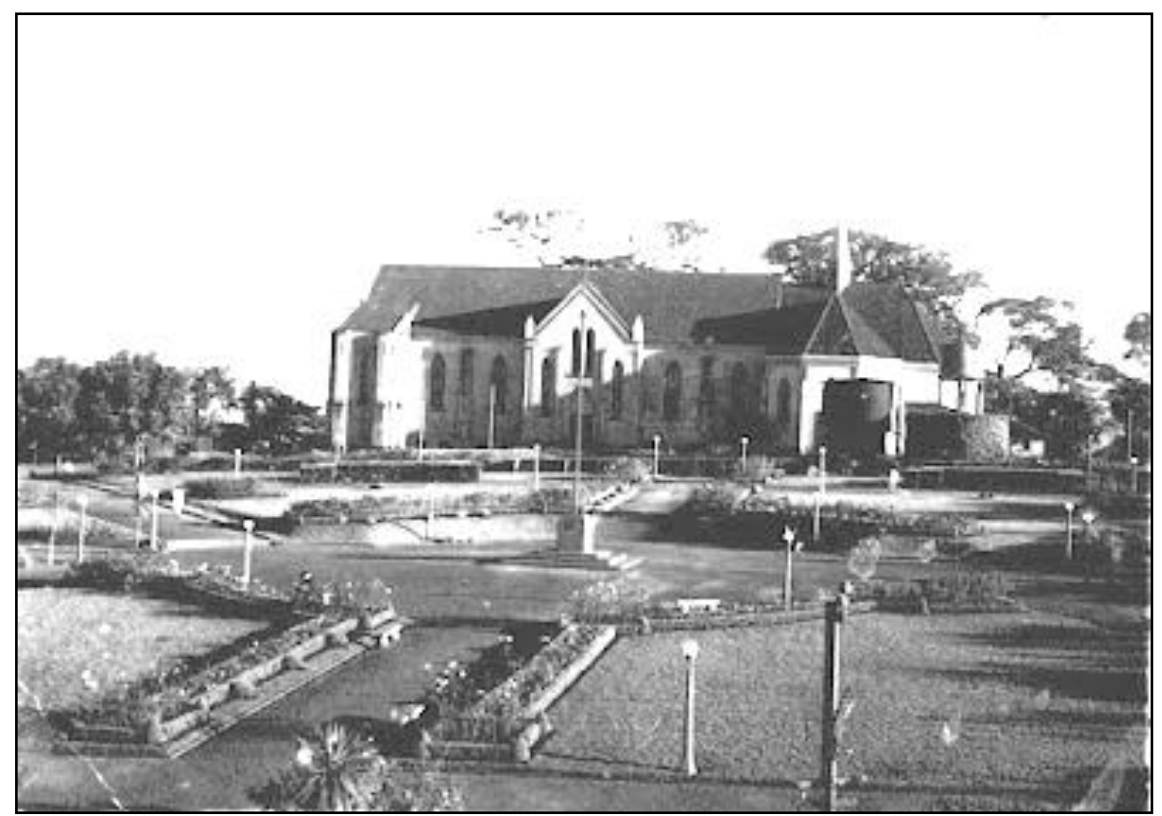

Fonte: Acervo Museu Histórico de Londrina, 2014.

No ano 2002, o governo municipal deu início à revitalização dos espaços urbanos centrais da cidade. Entre as intervenções foram incluídas alterações nos mobiliários, iluminação, segurança, higienização e calçamento. Além da retirada do comércio popular das praças e ruas.

Atualmente a praça é um elemento de composição urbanística e de embelezamento, destinado a circulação, encontros e manifestações urbanas (Figura 2). 


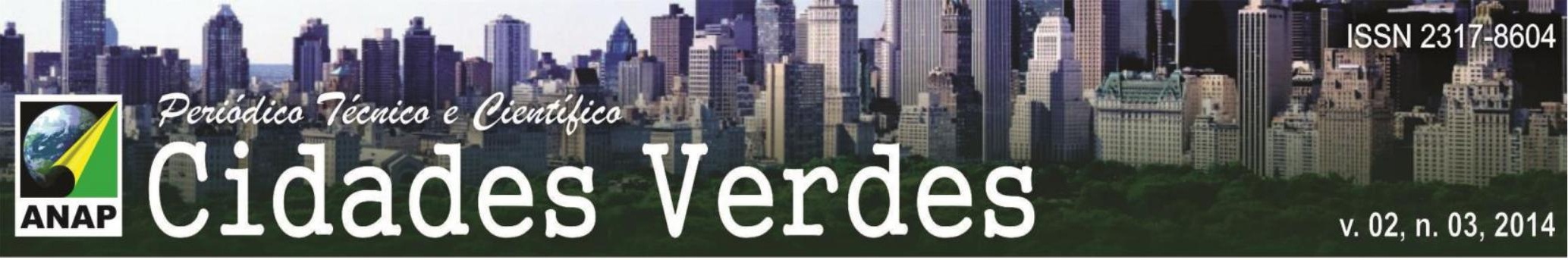

Figura 2: Praça Marechal Floriano Peixoto em 2014

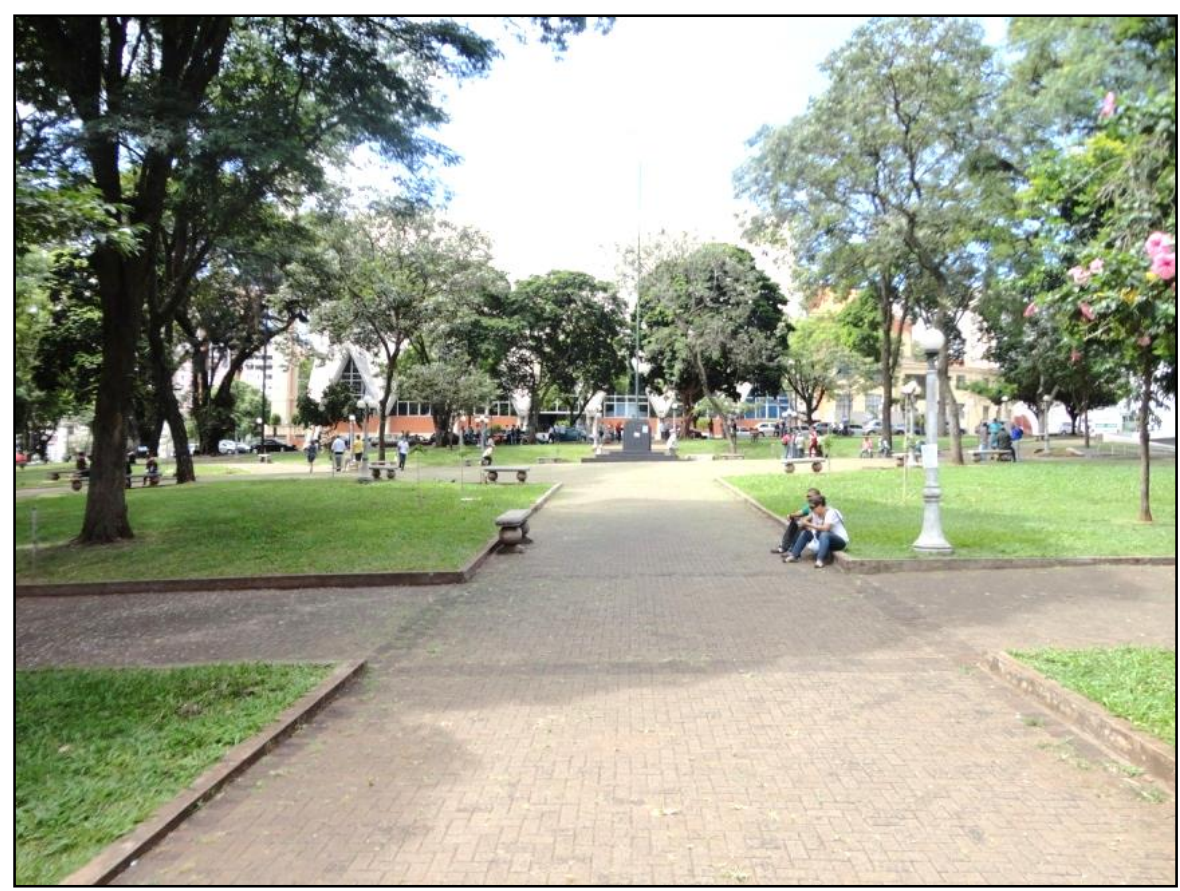

Fonte: Acervo Pessoal.

$\mathrm{Na}$ região central o Engenheiro da Companhia Melhoramentos Norte do Paraná, Alexandre Rasgulaeff, projetou a praça entre as Avenidas Paraná, São Paulo e Rio de Janeiro e a Travessa Padre Eugênio Herter, ao lado da Catedral Metropolitana. Sua área é de $11.633 \mathrm{~m}^{2}$, com 6 metros de desnível entre a Rua Padre Eugênio Herter, ao sul, em direção a Avenida Paraná, ao norte (Figura 3). 


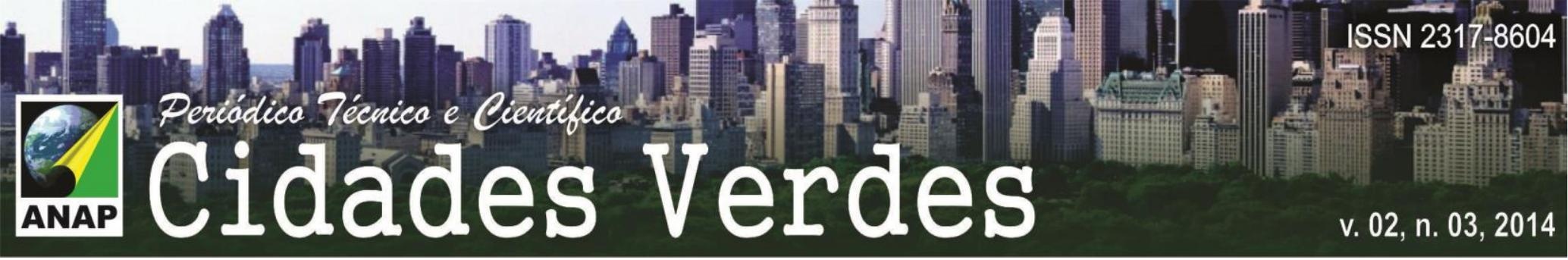

Figura 3: Localização da Praça

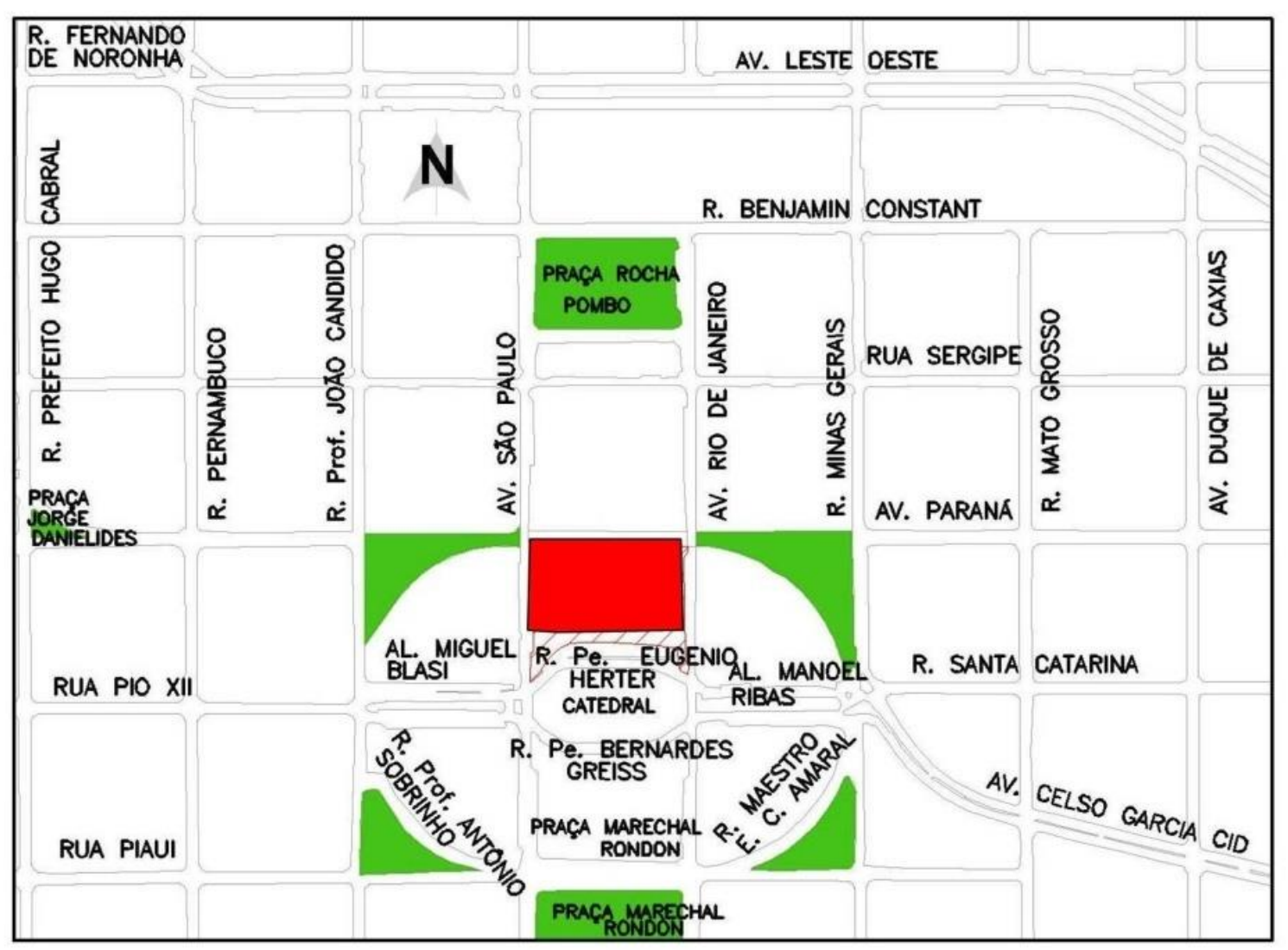

Fonte: Acervo Pessoal.

A pesquisa detectou que a Praça da Bandeira tem como uso para promover reuniões, atividades de lazer; sendo frequentada por pessoal do sexo masculino, acima de 40 anos, com baixa escolaridade, com os objetivos de descansar; sociabilização; exercício físico; passeios com crianças e como local de transito para outras regiões da cidade.

A renda familiar média mensal da amostra variou de um a três salários mínimos. Entre os entrevistados, 57\% informaram que em seus dias de folga do serviço preferem não permanecer em suas moradias, 34\% da amostra costumam ir a casas de parentes e/ou amigos, e 29\% preferem ir às praças. Já nos dias que permanecem em suas residências 33\% optam por assistir televisão e 15\% executam atividades domésticas.

Entra as pessoas pesquisadas $50 \%$ afirmou que frequentam as praças da cidade de Londrina. Das 25 pessoas que usufruem da Praça 43\% o fazem durante a 


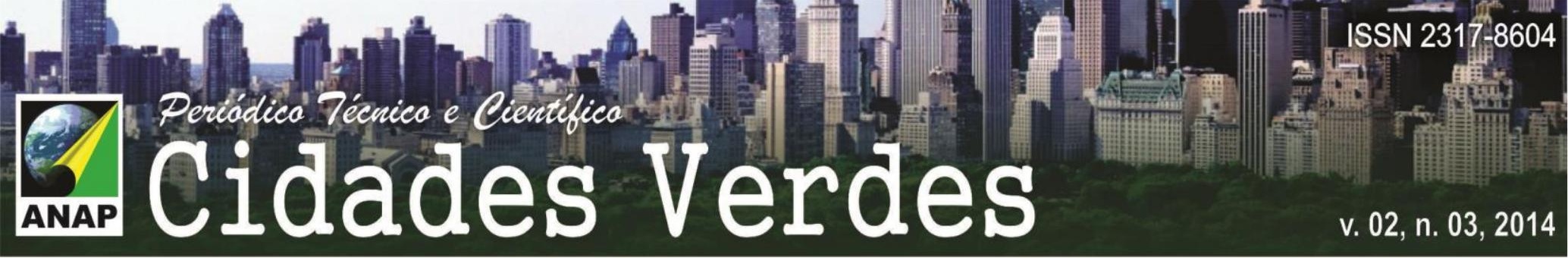

semana, sendo $56 \%$ no período da manhã. E metade dos indivíduos frequentam as praças por motivos diversos.

Os pontos mais críticos na percepção dos pesquisados para o estado de conservação dos equipamentos da Praça Marechal Floriano Peixoto são as lixeiras; sanitários; telefone público; bebedouro; piso; manutenção das estruturas; limpeza e segurança. Já os que se destacaram como de ótimo estado de conservação foram o traçado, ponto de ônibus, vegetação e localização.

A Praça da Matriz além da privilegiada localização e serviços a ela vinculados constituem-se em um espaço de passagem, lazer e entretenimento; seu uso, sua morfologia através da história, tem demonstrado a importância do seu papel para a comunidade como símbolo aglutinador da população. Assim esta pesquisa avaliou a Praça, e através da aquisição e reflexão destas informações será possível subsidiar a construção de propostas de intervenções neste espaço público.

\section{REFERÊNCIAS}

BRASIL. Lei no 6.766, de 19 de dezembro de 1979. Estabelece as diretrizes e parcelamento do solo para fins urbanos. Disponível em: < http://www.planalto.gov.br/ccivil_03/leis/L6766.htm>. Acesso em: 24 de jul. de 2014

BOVO, M. C.; ANDRADE, T. B. Produção do espaço histórico-cultural de Campo Mourão (PR) Brasil: um estudo de suas praças centrais. Revista Formação Online, v. 19, n. 1, p.3-24, 2012.

A significação, o uso e a representatividade social dos espaços públicos: o caso das praças São José e Getúlio Vargas e, Campo Mourão/ PR. Anais do V Encontro de Produção Científica e Tecnológica, 2010.

DA SILVA, M. C.; DA SILVA, A. B.; AMORIM, T. E. C. Condições de espaços públicos destinados a prática de Atividades Físicas na cidade de Pelotas/RS/Brasil. Revista Brasileira de Atividade Física e Saúde, vol.17, n.1, p. 28-32 2012.

DE ANGELIS, B. L. D. de. A Praça no Contexto das Cidades: o caso de Maringá - PR. Tese de (Doutorado em Geografia). Faculdade de Filosofia, Letras e Ciências Humanas - Universidade de São Paulo. SP, 2000.

DE ANGELIS, B. L. D.; ANGELIS NETO, G. A vegetação e as praças na cidade de Maringá/PR. Acta Scientiarum. v. 22 n. 2, p. 1455- 1461, 2000.

A praça no contexto da engenharia urbana - metodologia de avaliação. Acta Scientiarum. v. 21, p. 41-948, 1999.

GOMES, M. A. S. As Praças de Ribeirão Preto-SP: uma contribuição geográfica ao planejamento e a gestão dos espaços públicos. Dissertação de Mestrado. Universidade Federal de Uberlândia, Uberlândia, 2005 
